Review

\title{
An Overview of Genetic and Environmental Risk of Autism Spectrum Disorder
}

\author{
Jianjun Ou 1, Ruiting Liu ${ }^{2}$, Yidong Shen 1, Kun Xia², Jingping Zhao 1,* \\ 1 Department of Psychiatry \& Mental Health Institute of the Second Xiangya Hospital, Central South University, the China \\ National Clinical Research Center for Mental Health Disorders, National Technology Institute of Psychiatry, Key \\ Laboratory of Psychiatry and Mental Health of Hunan Province, Changsha, Hunan, China \\ 2 Center for Medical Genetics and School of Life Sciences, Central South University, Changsha, Hunan, China
}

Received October 8, 2018; Accepted December 6, 2018

\begin{abstract}
Autism Spectrum Disorder (ASD) is a neurodevelopmental disorder typically diagnosed in children in the first few years of life. Genetic studies have demonstrated a moderate to high heritability of ASD, but only a limited number of single nucleotide polymorphisms (SNPs) have been identified. Meanwhile, numerous single de novo rare variants and copy number variations have been detected in patients with ASD, which are likely caused by environmental factors. Here we provide an overview of genetic and environmental factors that may contribute to the risk of ASD and we recommend that further study should be focused on both genes and environmental factors, as well as their interactions with the expectation that epigenetic studies will lead to understanding the link between the environment and risk of ASD.
\end{abstract}

\section{KEYWORDS}

Genetic association; environmental risk factors; autism spectrum disorder

\section{INTRODUCTION}

Autism Spectrum Disorder (ASD) is a neurodevelopmental disorder characterized by 1) persistent deficits in social communication and social interaction across multiple contexts and 2) restricted, repetitive patterns of behavior, interests, or activities [1]. Symptoms of ASD are present in the early post-natal developmental period, and more than $70 \%$ patients with ASD have co-morbdities with other somatic diseases, developmental disorders, or behavioral conditions, such as epilepsy, gastrointestinal problems, intellectual disability, attention-deficit hyperactivity disorder, anxiety, depression, aggressive and selfinjurious behaviors, etc [2]. Therefore, ASD is considered to be a serious disorder that adversely affects individual health and often times leads to lifelong disability. However, in the absence of any effective pharmacological treatments and the need for special education and training as the major approach to care for the children with ASD, this disorder imposes a heavy burden on the family and society. The lifetime cost of individuals with ASD was estimated at 1.4-2.4 million dollars in the United States and 0.92-1.5 million pounds (the US \$1.4-2.2 million) in the United Kingdom [3]. In addition, in regions that lack special education resources, more than half of parental employment is greatly affected by the burden of childcare with the average loss of annual household income associated with having a child with ASD estimated to be RMB 44,077 (\$7,226) in China [4].

\footnotetext{
* Correspondence: Jingping Zhao, Email: zhaojingping@csu.edu.cn.
}

The prevalence of ASD has increased greatly over the past decades. While expanded diagnostic criteria may be a significant contributor to the rising prevalence in ASD, prevalence has increased from $0.5 / 1000$ in the $1960 \mathrm{~s}$ to $6.2-26.4 / 1000$ in the 2000s [5-9]. Recent data for autism and developmental disabilities from a monitor-ing network show the estimated prevalence of ASD to be 16.8/ 1000 (one in 59) in the United States [10]. A largescale study tracking 677,915 Danish children over several decades reported that changes in reporting pra-ctices might account for more than half $(60 \%)$ of the incr-ease in the observed prevalence of ASD [11]. However, this study did not consider other factors such as changes in envir-onmental exposures, which are likely to contributte to the continuing rising in prevalence $[12,13]$. In this review, we present recent findings in genetic and environmental studies with discussion of their roles in the pathogenesis of ASD and we provide our perspective of gene-environment interactions that may help to dis-sect the etiology of ASD.

\section{GENETIC VARIANTS ASSOCIATED WITH RISK OF ASD}

ASD is a complex disorder with strong genetic components. Twin and population-based studies have demonstrated that the heritability of ASD was high to 50-95\% [14$16]$. In the past ten years, multiple approaches have been used in the genetic study of ASD, including a genomewide association study (GWAS) [17], copy number variations (CNVs) analysis [18], whole-exome sequencing (WES) [19] and whole genome sequencing (WGS) [20]. 
These studies provide insight into the genetic etiology of ASD and implicate biological processes in the occurrence of ASD [21].

\section{Common variants}

GWAS have identified a few common genetic risk factors associated with ASD. The first large-scale GWAS was conducted in a cohort of 780 families ( $n=3,101$ subjects) with ASD children of European ancestry populations and a second cohort of 1,204 ASD patients and 6491 control subjects, and identified six single nucleotide polymorphisms (SNPs) at an intergenic region between cadherin $10(C D H 10)$ and cadherin 9 (CDH9) [17]. These two genes encoded neuronal cell-adhesion molecules, suggesting a role of neuronal cell-adhesion molecules in the pathogenesis of ASD. Meanwhile, linkage and association mapping study were conducted with 1031 multiplex autism families (1,553 affected offspring). While the initial analysis did not yield genome-wide significant asso- ciations, genotyping of top hits in additional families identified an SNP on chromosome 5p15 (-80 kb upstream of SEMA5A, a gene implicated in axonal guidance) associated with autism at genome-wide significance. The expression of SEMA5A was reduced in post-mortem human brains from subjects with autism, further implicating axonal guidance in the pathogenesis of ASD [22]. Subsequently, common variants located within MACROD2, CNTNAP2, CACNA1C, and CACNB2 were associated with ASD; however, all these studies were conducted in European ancestry populations [23-25]. Later, the first GWAS in a Han Chinese population identified multiple genes including TRIM33, BCAS2, AMPD1, DENND2C, and NRASCSDE1 on $1 \mathrm{p} 13.2$ as genetic susceptibility loci to autism, and these findings were replicated in three additional cohorts of family-based samples of European ancestry despite some genetic heterogeneity noted for these loci [26]. Table 1 presents a summary of these findings.

Table 1. Common variants associated with Autism Spectrum Disorder.

\begin{tabular}{|c|c|c|c|}
\hline Chr & Gene & SNP & Pubmed ID \\
\hline 1 & ACTN2 & rs2297956 & 19812673 \\
\hline 1 & AMPD1 & rs926938, rs761755 & 24189344 \\
\hline 1 & CSDE1 & rs8453, rs11558867, rs10489525 & 24189344 \\
\hline 1 & DENND2C & rs6537841, rs7539721 & 24189344 \\
\hline 1 & RASSF5 & rs11118968 & 22843504 \\
\hline 1 & SLC22A15 & rs12726299 & 22843504 \\
\hline 1 & TRIM33 & rs6537825, rs1102800,rs383773, rs3827735 & 24189344 \\
\hline 1 & TRIM33 & rs11582563, rs11585926, rs7511633, rs6661053 & 24189344 \\
\hline 2 & DNER & rs6752370 & 22843504 \\
\hline 2 & ERBB4 & rs1879532 & 22843504 \\
\hline 2 & GALNT14 & rs10205350 & 22843504 \\
\hline 2 & $P A R D 3 B$ & rs4675502 & 22843504 \\
\hline 3 & YEATS2 & rs263025, rs263030 & 22843504 \\
\hline 4 & ZNF827 & rs12331851 & 22843504 \\
\hline 5 & CTNND2 & rs6891903 & 22843504 \\
\hline 5 & FER & rs3797817 & 22935194 \\
\hline 5 & FLJ46010 & rs29456 & 22843504 \\
\hline 6 & CDKAL1 & rs7741604 & 22843504 \\
\hline 6 & $S L C 22 A 3$ & rs12194182 & 22843504 \\
\hline 7 & CNTNAP2 & rs1718101, rs7794745 & 22843504 \\
\hline 7 & RAC1 & rs836474 & 22843504 \\
\hline 7 & SDK1 & rs17134117 & 22935194 \\
\hline 8 & FAM135B & rs2056412 & 22935194 \\
\hline 10 & PCDH15 & rs1930165 & 22843504 \\
\hline 10 & SORCS1 & rs7910584 & 22843504 \\
\hline 11 & GUCY1A2 & rs11211996 & 22843504 \\
\hline 11 & NELL1 & rs1429793 & 22935194 \\
\hline 11 & $P C$ & rs7122539 & 22843504 \\
\hline 11 & PICALM & rs669556, rs618679, rs527162, rs2077815 & 24189344 \\
\hline 11 & ZBTB16 & rs3782000 & 22843504 \\
\hline 12 & TMEM132B & rs16919315 & 22843504 \\
\hline 14 & $P P P 2 R 5 C$ & rs7142002 & 20663923 \\
\hline 14 & SYNE2 & rs2150291 & 22843504 \\
\hline 16 & TAF1C & rs4150167 & 22843504 \\
\hline 17 & RPH3AL & rs7207517 & 22843504 \\
\hline 17 & SLC39A11 & rs9302952 & 22843504 \\
\hline 18 & LAMA1 & rs600695 & 22843504 \\
\hline 18 & $L I P G$ & rs2000813 & 22843504 \\
\hline 18 & MYOM1 & rs10853291 & 24189344 \\
\hline 20 & MACROD2 & rs4141463, rs14135, rs6110458, rs1475531 & 20663923 \\
\hline 20 & SLC23A2 & rs6053022 & 22843504 \\
\hline 21 & $E R G$ & rs2836439 & 22843504 \\
\hline
\end{tabular}


Common variants are very significant as genetic determinants of autism. A recent study using the whole-genome SNPs from a unique population-based family sample in Sweden estimated the narrow-sense heritability to be $52.4 \%$, which is mostly attributed to the common variants. However, no specific variant was found at a genomewide significance in this study [16]. This implies that many genetic variants remain undetected, possibly due to the limited sample size. Few previous genetic studies have considered thepossible role of environmental factors as well as their interactions with genetic variants. Unlike rare variants that may directly cause biological dysfunction, common genetic variants may affect the risk of ASD through their interaction with environmental factors, influencing the expression of genes and then leading to the development of ASD. Furthermore, the common variants found so far implicate many biological mechanisms including cell-adhesion molecules, axonal guidance, histone acetylation, calcium channel signal and transcription. This range of possible mechanisms certainly warants further studies that incorporate genetic and environmenttal factors simultaneously.

\section{Rare de novo variants}

The substantial research effort has been invested in atempts to discover rare variants that contribute to autism through copy number variations analysis, whole-exome sequencing and whole genome sequencing. The first significant copy number variations analysis was performed in 111 families with sporadic cases of autism, 47 families with multiple cases of autism and 99 control families. De novo CNVs were identified in $10 \%$ of patients with sporadic cases of autism, $3 \%$ of patients with affectted first-degree relatives, and $1 \%$ of controls without a diagnosis of autism. This indicates that de novo germline mutations account for a proportion of ASD [18]. Subsequently, more studies have searched for de novo mutations and found several sites or genes with de novo CNVs, located at 15q11-13,16p11.2, 15q24 or disrupting $N R X N$ 1, CNTN4, NLGN1, UBE3A, PARK2, RFWD2, FBXO40, SHANK3, NLGN4X, DPP6, DPP10, PCDH9, ANKRD11, DPYD, PTCHD1, SHANK2, SYNGAP1, DLGAP2 and DDX53-PTCHD [27-31] (Table 2).

Table 2. Copy number variations detected in individuals with Autism Spectrum Disorder.

\begin{tabular}{|c|c|c|c|c|}
\hline Chr & CNV Type & Region & Disrupted Genes & Pubmed ID \\
\hline 1 & dup & $1 q 25.1-q 25.2$ & RFWD2 & 19404257 \\
\hline 1 & del & $1 \mathrm{p} 21.3$ & $D P Y D$ & 18252227 \\
\hline 2 & del & 2p15-p16.1 & PEX13, FANCL & 16963482 \\
\hline 2 & ins & $2 \mathrm{p} 16.3$ & NRXN1 & 18179900 \\
\hline 2 & del & $2 \mathrm{p} 16.4$ & NRXN1 & 17322880 \\
\hline 2 & dup & $2 \mathrm{q} 14.1$ & DPP10 & 18252227 \\
\hline 3 & $\mathrm{del} / \mathrm{dup}$ & $3 p 26.3$ & CNTN4 & 18349135 \\
\hline 3 & dup & $3 q 26.31$ & NLGN1 & 20010541 \\
\hline 3 & dup & $3 q 13.33$ & $F B X 040$ & 19404257 \\
\hline 6 & del & $6 \mathrm{q} 25.2-\mathrm{q} 27$ & PARK2 & 19404257 \\
\hline 6 & del & $6 p 21.32$ & SYNGAP1 & 19196676 \\
\hline 7 & del & $7 q 36.2$ & $D P P 6$ & 18252227 \\
\hline 8 & dup & 8p23.3 & DLGAP2 & 17630015 \\
\hline 11 & del & 11q13.3-q13.4 & SHANK2 & 20531469 \\
\hline 13 & dup & $13 q 21.32$ & РCDH9 & 18252227 \\
\hline 15 & $\mathrm{del} / \mathrm{dup}$ & $15 q 13$ & FAN1, MTMR10, TRPM1, KLF13, OTUD7A, CHRNA7 & 27459725 \\
\hline 15 & dup & $15 q 11-13$ & $U B E 3 A$ & 19404257 \\
\hline 15 & $\mathrm{del} / \mathrm{dup}$ & $15 q 24$ & More than 50 genes & 21480499 \\
\hline 16 & $\mathrm{del} / \mathrm{dup}$ & $16 \mathrm{p} 11.2$ & ATP10A, GABRB3 & 18184952 \\
\hline 16 & del & $16 q 24.3$ & ANKRD11 & 18252227 \\
\hline 22 & del & $22 q 13.3$ & SHANK3 & 17173049 \\
\hline $\mathrm{X}$ & $\mathrm{del} / \mathrm{dup}$ & $\mathrm{X}$ & $N L G N 4 X$ & 12669065 \\
\hline $\mathrm{X}$ & del & Xp22.11 & PTCHD1 & 18252227 \\
\hline
\end{tabular}

A whole exome study of ASD first identified de novo single point mutations in 4 out of 20 probands, particularly among more severely affected individuals, in FOXP1, GRIN2B, $S C N 1 A$ and $L A M C 3$ [19]. Later, more than one hundred mutational variants were detected; for example, at $C H D 8$, POGZ, NTNG1, KATANAL2, SCN2A, GIGYF2, MYT1L, CUL3, DOCK8, and ZNF292 [32-34]. Some rare variants have been reported in multiple studies. Recently, 18 new candidate genes were found in ASD by using a large whole-genome sequencing in more than five thousand ASD families; and there were an average of 73.8 de novo single nucleotide variants and 12.6 de novo insertions and deletions or copy number variations per ASD subject [35]. Many rare mutations have been identified in at least three independent studies (Table 3).

While contributing little to the heritability, all these studies suggest that de novo rare variants play a role in the etiology of ASD. The major pathways implicated for biological mechanisms include synaptic formation and stabilization, the growth of dendrites and axons, neuron branches and migration [36]. A whole-exome sequencing study in more than 2,500 simplex families, each having a single child with ASD, estimated that coding de novo mutations contribute to abo- 
ut $30 \%$ of all simplex diagnoses [32]. A whole-genome sequencing study of 85 family-Quads (i.e., parents with one affected and one unaffected child) found $69.4 \%$ of the unaffected siblings carried different ASD-relevant mutations [20]. These studies indicate that rare de novo mutations contribute substantially to individual liability and emphasizes that substantial genetic heterogeneity exists in ASD. However, these rare de novo variants may be due to environmental exposures.

Table 3. Rare mutations that have been identified by at least three studies of Autism Spectrum Disorder.

\begin{tabular}{|c|c|c|}
\hline Chr & Gene & Pubmed ID \\
\hline 2 & PRKCQ, CELF2, CAMK1D & $29700473,28965761,26749308$ \\
\hline 2 & TCERG1L & $28965761,25363768,26749308$ \\
\hline 2 & ECHS1, ANO9, PHRF1 & $28965761,25363768,25961944$ \\
\hline 2 & $M S 4 A 4 A, V W C E$ & $28965761,29700473,25363768$ \\
\hline 2 & $C 2 C D 3$ & $28965761,25961944,26749308$ \\
\hline 2 & MMP8 & $25363768,28965761,26749308$ \\
\hline 3 & $N L R X 1, C B L, M C A M$ & $25961944,28965761,25363768$ \\
\hline 3 & $M F R P, G R I K 4$ & $25363768,26749308,28965761$ \\
\hline 3 & $M E D 13 L$ & $26749308,28965761,25363768$ \\
\hline 3 & NCOR2, TMEM132B & $25363768,28965761,26749308,29700473$ \\
\hline 4 & CARKD, DCUN1D2, GAS6-AS2 & $25363768,28965761,29700473$ \\
\hline 4 & CCDC88C, SMEK1, TRIP11 & $25961944,28965761,25363768$ \\
\hline 5 & CREBBP, ADCY9, C16orf96 & $25961944,25363768,26749308$ \\
\hline 6 & MYO1D, ASIC2, TMEM132E & $25363768,26749308,28965761$ \\
\hline 7 & ANKFN1, MSI2 & $29700473,26749308,28965761$ \\
\hline 7 & TRAPPC8, KLHL14 & $28965761,25363768,25961944$ \\
\hline 7 & HDHD2 & $25363768,28965761,29700473$ \\
\hline 7 & PIK3R2, IFI30, ZNF43 & $28965761,25363768,29700473$ \\
\hline 8 & BRSK1, NLRP11 & $26749308,25961944,28965761$ \\
\hline 8 & CPSF3, PDIA6 & $25961944,26749308,28965761$ \\
\hline 9 & SRBD1, PRKCE & $25363768,28965761,29700473$ \\
\hline 9 & FLJ30838, BCL11A & $26749308,29700473,25363768$ \\
\hline 9 & MBD5 & $26749308,23160955,25363768$ \\
\hline 9 & NR4A2, UPP2 & $25363768,29700473,26749308$ \\
\hline 12 & CSRNP1, CTNNB1 & $29700473,26749308,23160955$ \\
\hline 12 & CACNA1D, CACNA2D3 & $25418537,26749308,28965761,29700473$ \\
\hline 15 & TRIO, FBXL7 & $25363768,28965761,26749308$ \\
\hline 21 & FBXO10, CNTNAP3, PIP5K1B & $25363768,28965761,26749308$ \\
\hline 21 & PIP5K1B, APBA1, PTAR1 & $26749308,28965761,25363768$ \\
\hline 21 & FBXO10, CNTNAP3, PIP5K1B & $25363768,28965761,26749308$ \\
\hline 22 & DNM1, PTGES & $28965761,25363768,25961944$ \\
\hline
\end{tabular}

\section{ENVIRONMENTAL RISK FACTORS}

The range of environmental risk factors in etiological studies of ASD is very broad and includes not only factors in the physical environment such as air pollution, heavy metals, toxic substances, microorganism, and pharmacyological medications, but also includes physiological, infectious and psychosocial environmental exposures to which parents and/or offspring were exposed before or after birth. For example; advanced parental age, allergic and autoimmune diseases, mental stress and disorders, delivery mode and premature birth have been suggested as risk factors for ASD [37]. A rigorous quantitative estimate of genetic heritability of ASD and shared environment with twin pairs have indicated that a large proportion of the variance in the liability of ASD (58\%) can be explained by the shared environment in addition to moderate genetic heritability (38\%) [38]. Furthermore, many environmental factors that may interact with genes have been associated with the onset of ASD, and their influence may distribute across a wide range of the early life, from germ cell to the early posthatal development [37,39] (Table 4).

\section{Advanced parental age}

Advanced parental age has been suggested as a risk factor for ASD. A Western Australia population-based study comprising 465 cases, 481 siblings of the cases and 1,313 controls has shown that ASD patients tend to be offspring of older parents [40]. Additionally, a meta-analysis of epidemiological studies showed that advanced paternal age is a risk factor for ASD in the offspring [41]. Another review and meta-analysis also supported an association between advancing maternal age and risk of autism [42]. The possible underlying biological mechanism might be that de novo genomic aberrations such as CNVs, mutations, or epigenetic alterations are associated with aging $[43,44]$. 
Table 4. Main environmental factors associated with Autism Spectrum Disorder.

\begin{tabular}{ll}
\hline Main Type & Details \\
\hline Physical factors & \\
Air pollution & PM2.5, $\mathrm{PM} 10, \mathrm{NO}_{2}, \mathrm{O} 3$, etc. \\
Heavy metals & $\begin{array}{l}\text { Lead, mercury, } \text { etc. } \\
\text { Pexticides, herbicides, other endocrine-disrupting chemicals (fragrance, } \\
\text { testosterone, } \text { etc.) }\end{array}$ \\
Medication drugs & $\begin{array}{l}\text { Exposure to selective serotonin reuptake inhibitor (SSRIs), Benzodiazepines, } \\
\text { Valproate, or Antiviral drugs (acyclovir, etc.) medication during pregnancy }\end{array}$ \\
Physiological and pathological factors & Paternal and maternal age \\
Advanced age & Cesarean delivery \\
Delivery mode & Asthma, Atopic Dermatitis, etc. \\
Allergic and autoimmune diseases & Bacterial or viral infections, Toxoplasma gondii during pregnancy \\
Infection and parasite & Induced and threatened abortion \\
Abortion & The gestational week of childbirth <37 weeks \\
Premature birth & \\
Psychological factors & Family issues and psychosocial stress during pregnancy \\
Mental stress & Major depressive disorder and other psychiatric problems \\
Mental disorders &
\end{tabular}

\section{Gestational conditions}

The association between infections in pregnancy and ASD has long been noted. In the 1970s, Stella Chess found a high prevalence of autism in children with congenital rubella syndrome (CRS), which was 200 times that in the general population [45]. Although rubella infections have been greatly reduced in the past few decades, recent evidence linking ASD to rubella are still found [46]. In addition, viral, bacterial and parasitic infections including flu, measles, mumps, chickenpox, polio, pneumonia, sinusitis, tonsillitis, and toxoplasma gondii, have also been associated with ASD in retrospective and prospective studies [47-49]. Recently, in a large prospective study comprising 874 ASD and 874 matched controls from the Finnish national birth cohort ( $n=1.2$ million) and the national psychiatric registries, parasitic infection with toxoplasma gondii was consistently associated with ASD [50]. The hypothesis of maternal immune activation (MIA) may explain the link between diverse maternal infections and ASD [51].

Psychosocial stress during pregnancy may increase the risk of developmental abnormallities in offspring and has been identified as a risk factor for mental disorder in children [52-54]. In the early 1990s, Ward reported that mothers of autistic children were more likely to experience family issues and diagnoses of psychiatric problems than the mothers of normal children [55]. A subsequent study found that mothers of children with ASD were more likely to have suffered from psychosocial stress in pregnancy than mothers of typically developed children. A higher number of maternal psychosocial stressors was observed at 21-32 weeks gestation, with a peak at 25-28 weeks, who gave birth to children with autism [56]. Although genestress interaction might be a potential explanation, empirical studies are relatively scarce [54].

Mothers who used medications during pregnancy might increase the risk of ASD in offspring. A Danish population-based case-control study comprising 473 ASD and 4,712 controls showed that maternal use of medicine during pregnancy may have a 1.5 fold increase in the risk of ASD in offspring. Additionally, a detailed analysis of different types of medications used during pregnancy indicated that the use of psychoactive drugs was associated with ASD [57]. Subsequently, a number of studies reported that maternal exposure to selective serotonin reuptake inhibitors (SSRIs) during pregnancy could increase the risk of ASD in offspring [58-60]. However, the evidence of the association between SSRIs and ASD lacks consistency [61,62]. Additionally, some neuropsychiatric drugs such as benzodiazepines, valproate, and antiviral drugs such as acyclovir are banned for pregnant women due to their severe adverse effect on fetal nervous system development.

\section{Obstetric and perinatal conditions}

Threatened abortion has been considered a risk factor for ASD. A meta-analysis of studies showed that threatened abortion could increase the risk of ASD in offspring by $81 \%$ [63]. This possible association is confounded by the fact that threatened abortion (a) has been associated with many child developmental disorders and (b) is likely caused by many factors such as fetal genetic defects, the maternal reproductive environment, maternal exposure to a toxic and harmful substance as well as physical and psychological trauma. Therefore the associ-ation between threatened abortion and ASD might be complicated and the two conditions might simply share a number of common risk factors. One population-based study indicated that mothers of children with ASD had a higher prevalence of threatened abortion than mothers of controls, however the cases did not differ from that seen in their siblings [40]. Another population-based study investigated all live singleton births in Western Australia between January 1984 and December 1999 ( $n=383,153)$ and found that threatened abortion was only associated with an increased risk of ASD with intellectual disability, but not for ASD without intellectual disability [64]. Therefore, further studies are needed that account for comprehensive phenotype measurements of children with 
ASD, the possible causes of threatened abortion as well as other potential genetic and environmental factors.

Premature birth ( $<37$ weeks) is associated with many developmental disorders due to the immaturity of the nervous system and has been identified as a significant risk factor for ASD [65]. A previous small retrospective study $(n=91)$ found twenty-six percent of extremely preterm infants were positive in autism screening [66]. In a subsequent prospective study investigating all births at less than 26 weeks of gestation in the United Kingdom and Ireland in 1995, extremely preterm births had significant impairment in social communication compared to their classmates, and $8 \%$ of extremely preterm births were diagnosed with ASD [67]. In a recent report from the Autism and Developmental Disabilities Monitoring (ADDM) Network, the average population attributable fractions of premature delivery were $4.2 \%$ for the 1994 cohort ( $n=703$ ) and $2.0 \%$ for the 2000 cohort $(n=1,339)$ [68]. However, there are still some inconsistencies. For example, the significant association between preterm birth and ASD was not found in a cohort study in Sweden, which was with 408 ASD and 2,040 matched controls [69]. In another cohort study in Denmark with 473 ASD and 4,712 matched controls, the association between preterm birth and ASD was significant in the crude analysis but became less significant when adjusted for mother and fathers age, mothers citizenship, birthweight, Apgar, birth defect and irregular fetal position [57]. It must be noted that premature delivery is not an exogenous variable since it may be affected by many other environmental factors and the maternal genetic background. In some cases, prematurity may indeed be a key mediator of risk for autism. Therefore, one or more studies with rigorous design and sophisticated analyses may be needed to validate or invalidate this association.

Cesarean delivery is common in more developed countries and has increased rapidly along with economic growth in less developed countries such as China [70]. Although cesarean birth can avoid many adverse events of natural childbirth, it may increase the risk of ASD in offspring significantly [71]. Two population-based studies found that ASD patients were more likely to be delivered by an elective or emergency cesarean section [40, 69]. In a recent cohort study of ASD, the average population attributable fractions for cesarean birth were $7.9 \%$ for the 1994 cohort and $6.7 \%$ for the 2000 cohort [68]. Nevertheless, the association between cesarean birth and ASD in offspring is still inconclusive. A Danish population-based study found that only scheduled cesarean sections were associated with infantile autism, and its significance was influenced by many factors such as parental age, birth weight, birth defects and aberent fetal presentations [57]. Although the mechanism underlying this association is unclear, anesthesia during childbirth, the absence of passage through the birth canal, lack of exposure to the maternal vaginal microbiome, and possibly other factors might be involved.

\section{Environmental pollution}

Environmental pollution such as air pollution, pesticides, herbicides, endocrine-disrupting chemicals (EDC), and heavy metals can persistently affect offspring from exposures across a range of developmental stages from the germ cell stage through postnatal early childhood and lead to an increased risk of ASD [37,72-74]. Most studies focus on exposure in one or more of critical windows, including (1) the first to the third trimester of pregnancy, (2) the entire pregnancy, and (3) the postnatal period. Fewer studies have been conducted to examine the effect of exposure throughout all of the critical developmental windows. Flores-Pajot et al. reported that exposure to PM2.5 and NO2 during pregnancy or after birth was associated with an increase in the risk of ASD while exposures to 03 was weakly associated with ASD during either the third trimester of pregnancy or the entire pregnancy [75]. These findings imply that the effect of maternal exposure to air pollution on neural development in offsprings may vary with the type of pollution and the period of pregnancy. Although many studies from the United States indicate that exposure to air pollution in early life is associated with ASD in children, European data showed that early-life exposure to low levels of NOx and $\mathrm{PM}_{10}$ from road traffic did not appear to increase the risk of ASD [76].

Furthermore, the effect of environmental factors or hormone exposures may have differences by sex of the offspring. First, exposure to fragrances may lead to male bias in the risk of ASD, and the possible mechanism is that men may lack OXYP+ and AVPR+ neurons [77]. Second, maternal exposure to prenatal and neonatal testosterone of fetal origin may be associated with sexual dimorphism in ASD [78]. Finally, some toxic exposures may interfere with conduction of electrical or chemical signals during development and cause neurodevelopmental disorders, whereas other exposures may disturb the endocrine and immune systems and evoke abnormal maternal immune responses which may, in turn, increase the risk of ASD [73].

\section{SUMMARY}

While many genetic variants and environmental risk factors have been identified in ASD, more attention should be paid to the interacttion between genes and the environment. To conduct these types of studies, cohorts will need to be well-characterized in terms of genetics and in terms of accurate measurements of maternal exposures to environmental factors. Accounting for both classes of variables (gene and environment) should increase the power to detect genetic variants that may be more robustly associated with ASD. In the MIA hypothesis, maternal immune activation during pregnancy is considered as a general liability of risk of ASD and it may make an individual more vulnerable to the influence of genetic and environmental factors [51]. In terms of epigenetic mechanisms, environmental factors can mod-ify the expression of genes via epigenetic changes which may thereby lead to an increased risk of ASD [79]. All of these hypotheses and potential interactions among them 
need to be further tested with more empirical studies. For example, based on data from the Childhood Autism Risks from Genetics and Environment (CHARGE) study which started in 2006 [80], Kim et al. reported in 2017 that global copy number variation (duplication) may interact with certain environmental factors (ozone) to increase the susceptibility of ASD [81].

We acknowledge the challenges in conducting such studies, especially when it comes to the interaction between genes and the environment. First, quantitative measures of the exposure to many environmental factors of many types are a challenge to perform and many will need to be carried out over various periods of time in order to adequately document the levels and duration of such exposures and how those attributes relate to various developmental intervals. Not only are those measurements of environmental factors costly and time-consuming, genotyping large numbers of samples also demands substantial research resources.

Study of both genetic and environmental factors associated with ASD can provide new evidence for effective prevention or to identify novel drug targets for developing future therapies for ASD. Given that, the cost of chipbased whole genome genotyping has dropped, it will be possible to conduct one or more large-scale studies on population-based samples. A cohort study with a followup of a number of parents, especially for those exposed to specific environmental factors of interest to examine how the environment may cause the development of ASD or other neurodevelopment disorder should be undertaken. Those studies would provide opportunities to identify high-risk sub-populations for prevention or early therapeutic treatment(s). Finally, additional patient cohorts need to be established in order to monitor other comorbidities of ASD children during their critical stages of development.

\section{CONFLICT OF INTERESTS}

The authors declare that there is no conflict of interest regarding the publication of this paper.

\section{ACKNOWLEDGMENTS}

This study was supported by funding from The National Natural Science Foundation of China (No. 81601197 and 81730036) and the Major State Basic Research Development Program of China (973 Program, No. 2012CB-517901).

\section{REFERENCES}

1. American Psychiatric Association. Diagnostic and Statistical Manual of Mental Disorders (DSM-5), 5th ed. Washington, DC (US): American Psychiatric Association Publishing; 2013.

2. Lai MC, Lombardo MV, Baron-Cohen S. Autism. Lancet. 2014;383(9920):896-910.
3. Buescher AV, Cidav Z, Knapp M, Mandell DS. Costs of autism spectrum disorders in the United Kingdom and the United States. JAMA Pediatr. 2014; 168 (8):721-8.

4. Ou JJ, Shi LJ, Xun GL, Chen C, Wu RR, Luo XR, et al. Employment and financial burden of families with preschool children diagnosed with autism spectrum disorders in urban China: results from a descriptive study. BMC Psychiatry. 2015;15:3.

5. Lotter V. Epidemiology of autistic conditions in young children. Social psychiatry. 1966;1(3):124-35.

6. Elsabbagh M, Divan G, Koh YJ, Kim YS, Kauchali S, Marcin C, et al. Global prevalence of autism and other pervasive developmental disorders. Autism Res. 2012;5(3):160-79.

7. Kim YS, Leventhal BL, Koh YJ, Fombonne E, Laska E, Lim EC, et al. Prevalence of autism spectrum disorders in a total population sample. Am J Psychiatry. 2011;168(9):904-12.

8. Saemundsen E, Magnusson P, Georgsdottir I, Egilsson E, Rafnsson V. Prevalence of autism spectrum disorders in an Icelandic birth cohort. BMJ Open. 2013;3(6):e002748.

9. Russell G, Rodgers LR, Ukoumunne OC, Ford T. Prevalence of parent-reported ASD and ADHD in the UK: findings from the Millennium Cohort Study. J Autism Dev Disord. 2014; 44(1):31-40.

10. Baio J, Wiggins L, Christensen DL, Maenner MJ, Daniels J, Warren Z, et al. Prevalence of Autism Spectrum Disorder Among Children Aged 8 Years - Autism and Developmental Disabilities Monitoring Network, 11 Sites, United States, 2014. Mmwr Surveill Summ. 2018;67(6):1-23.

11. Hansen SN, Schendel DE, Parner ET. Explaining the increase in the prevalence of autism spectrum disorders: the proportion attributable to changes in reporting practices. JAMA Pediatr. 2015;169(1):56-62.

12. Herbert MR. Contributions of the environment and environmentally vulnerable physiology to autism spectrum disorders. Curr Opin Neurol. 2010; 23(2): 103-10.

13. Lyall K, Croen L, Daniels J, Fallin MD, Ladd-Acosta C, Lee BK, et al. The changing epidemiology of autism spectrum disorders. Annu Rev Public Health. 2017; 38:81-102.

14. Colvert E, Tick B, McEwen F, Stewart C, Curran SR, Woodhouse E, et al. Heritability of autism spectrum disorder in a UK population-based twin sample. JAMA Psychiatry. 2015; 72(5):415-23.

15. Sandin S, Lichtenstein P, Kuja-Halkola R, Larsson H, Hultman CM, Reichenberg A. The familial risk of autism. JAMA. 2014;311(17):1770-7.

16. Gaugler T, Klei L, Sanders SJ, Bodea CA, Goldberg AP, Lee $\mathrm{AB}$, et al. Most genetic risk for autism resides with common variation. Nat Genet. 2014;46(8):881-5.

17. Wang K, Zhang HT, Ma DQ, Bucan M, Glessner JT, Abrahams $\mathrm{BS}$, et al. Common genetic variants on 5 p14.1 associate with autism spectrum disorders. Nature. 2009;459(7246): 528-33.

18. Sebat J, Lakshmi B, Malhotra D, Troge J, Lese-Martin C, Walsh T, et al. Strong association of de novo copy number mutations with autism. Science. 2007;316 (5823):445-9.

19. O'Roak BJ, Deriziotis P, Lee C, Vives L, Schwartz JJ, Girirajan $\mathrm{S}$, et al. Exome sequencing in sporadic autism spectrum disorders identifies severe de novo mutations. Nat Genet. 2011;43(6):585-9.

20. Yuen RK, Thiruvahindrapuram B, Merico D, Walker S, Tammimies $\mathrm{K}$, Hoang $\mathrm{N}$, et al. Whole-genome sequencing of quartet families with autism spectrum disorder. Nat Med. 2015;21(2):185-91.

21. State MW, Sestan N. The emerging biology of autism spectrum disorders. Science. 2012;337(6100): 1301-3.

22. Weiss LA, Arking DE, Consortium JHA. A genome-wide linkage and association scan reveals novel loci for autism. Nature. 2009;461(7265):802-U62. 
23. Anney R, Klei L, Pinto D, Regan R, Conroy J, Magalhaes TR, et al. A genome-wide scan for common alleles affecting risk for autism. Hum Mol Genet. 2010;19(20):4072-82.

24. Anney R, Klei L, Pinto D, Almeida J, Bacchelli E, Baird G, et al. Individual common variants exert weak effects on the risk for autism spectrum disorders. Hum Mol Genet. 2012; 21(21):4781-92.

25. Cross-Disorder Group of the Psychiatric Genomics C. Identification of risk loci with shared effects on five major psychiatric disorders: a genome-wide analysis. Lancet. 2013; 381(9875):1371-9.

26. Xia K, Guo H, Hu Z, Xun G, Zuo L, Peng Y, et al. Common genetic variants on $1 \mathrm{p} 13.2$ associate with risk of autism. Mol Psychiatry. 2014;19(11):1212-9.

27. Glessner JT, Wang K, Cai G, Korvatska O, Kim CE, Wood S, et al. Autism genome-wide copy number variation reveals ubiquitin and neuronal genes. Nature. 2009;459(7246): 56973.

28. Pinto D, Pagnamenta AT, Klei L, Anney R, Merico D, Regan $\mathrm{R}$, et al. Functional impact of global rare copy number variation in autism spectrum disorders. Nature. 2010;466 (7304):368-72.

29. Levy D, Ronemus M, Yamrom B, Lee YH, Leotta A, Kendall J, et al. Rare de novo and transmitted copy-number variation in autistic spectrum disorders. Neuron. 2011;70(5):886-97.

30. Marshall CR, Noor A, Vincent JB, Lionel AC, Feuk L, Skaug J, et al. Structural variation of chromosomes in autism spectrum disorder. Am J Hum Genet. 2008; 82(2):477-88.

31. Guo H, Peng Y, Hu Z, Li Y, Xun G, Ou J, et al. Genome-wide copy number variation analysis in a Chinese autism spectrum disorder cohort. Sci Rep. 2017;7: 44155.

32. Iossifov I, O'Roak BJ, Sanders SJ, Ronemus M, Krumm N, Levy D, et al. The contribution of de novo coding mutations to autism spectrum disorder. Nature. 2014;515 (7526): 216-21.

33. Muers M. Human genetics: Fruits of exome sequen-cing for autism. Nature reviews Genetics. 2012;13 (6):377.

34. Wang TY, Guo H, Xiong B, Stessman HAF, Wu HD, Coe BP, et al. De novo genic mutations among a Chinese autism spectrum disorder cohort. Nature Communications. 2016; 7: 13316.

35. RK CY, Merico D, Bookman M, J LH, Thiruvahin-drapuram $B$, Patel RV, et al. Whole genome sequencing resource identifies 18 new candidate genes for autism spectrum disorder. Nat Neurosci. 2017; 20(4):602-11.

36. Kim YS, Leventhal BL. Genetic epidemiology and insights into interactive genetic and environmental effects in autism spectrum disorders. Biol Psychiatry. 2015;77(1): 66-74

37. Sealey LA, Hughes BW, Sriskanda AN, Guest JR, Gibson AD Johnson-Williams L, et al. Environmental factors in the devleopment of autism spectrum disorders. Environ Int. 2016;88:288-98.

38. Hallmayer J, Cleveland S, Torres A, Phillips J, Cohen B, Torigoe T, et al. Genetic Heritability and Shared Environmental Factors Among Twin Pairs With Autism. Arch Gen Psychiat. 2011;68(11):1095-102.

39. Mandy W, Lai MC. Annual Research Review: The role of the environment in the developmental psychopathology of autism spectrum condition. J Child Psychol Psychiatry. 2016; 57(3):271-92.

40. Glasson EJ, Bower C, Petterson B, de Klerk N, Chaney G, HalImayer JF. Perinatal factors and the development of autism: a population study. Arch Gen Psychiatry. 2004; 61 (6):61827

41. Hultman CM, Sandin S, Levine SZ, Lichtenstein P, Reichenberg A. Advancing paternal age and risk of autism: new evidence from a population-based study and a meta-analysis of epidemiological studies. Mol Psychiatry. 2011;16(12): 1203-12.
42. Sandin S, Hultman CM, Kolevzon A, Gross R, Mac-Cabe JH, Reichenberg A. Advancing maternal age is associated with increasing risk for autism: a review and meta-analysis. J Am Acad Child Psy. 2012; 51(5):477-86.

43. Kong A, Frigge ML, Masson G, Besenbacher S, Sulem P, Magnusson $\mathrm{G}$, et al. Rate of de novo mutations and the importance of father's age to disease risk. Nature. 2012;488 (7412):471-5.

44. Buizer-Voskamp JE, Blauw HM, Boks MPM, van Eijk KR, Veldink JH, Hennekam EAM, et al. Increased paternal age and the influence on burden of genomic copy number variation in the general population. Hum Genet. 2013;132 (4): 443-50.

45. Chess S. Autism in children with congenital rubella. J Autism Child Schizophr. 1971;1(1):33-47.

46. Hutton J. Does Rubella Cause Autism: A 2015 Reappraisal? Front Hum Neurosci. 2016;10:25.

47. Knuesel I, Chicha L, Britschgi M, Schobel SA, Bodmer M, Hellings JA, et al. Maternal immune activation and abnormal brain development across CNS disorders. Nat Rev Neurol. 2014;10(11):643-60.

48. Estes ML, McAllister AK. Immune mediators in the brain and peripheral tissues in autism spectrum disorder. Nat Rev Neurosci. 2015;16(8):469-86.

49. Patterson PH. Immune involvement in schizophrenia and autism: etiology, pathology and animal models. Behav Brain Res. 2009;204(2):313-21.

50. Spann MN, Sourander A, Surcel HM, Hinkka-Yli-Salomaki S, Brown AS. Prenatal toxoplasmosis antibody and childhood autism. Autism Res. 2017; 10(5): 769-77.

51. Estes ML, McAllister AK. Maternal immune activation: Implications for neuropsychiatric disorders. Science. 2016; 353(6301):772-7.

52. Beards S, Gayer-Anderson C, Borges S, Dewey ME, Fisher HL, Morgan C. Life events and psychosis: a review and meta-analysis. Schizophr Bull. 2013; 39 (4):740-7.

53. Holtzman CW, Trotman HD, Goulding SM, Ryan AT, Macdonald AN, Shapiro DI, et al. Stress and neurodevelopmental processes in the emergence of psychosis. Neuroscience. 2013;249:172-91.

54. van Winkel R, Stefanis NC, Myin-Germeys I. Psychosocial stress and psychosis. A review of the neurobiological mechanisms and the evidence for gene-stress interaction. Schizophr Bull. 2008;34(6): 1095-105.

55. Ward AJ. A comparison and analysis of the presence of family problems during pregnancy of mothers of "autistic" children and mothers of normal children. Child Psychiatry Hum Dev. 1990;20(4):279-88.

56. Beversdorf DQ, Manning SE, Hillier A, Anderson SL, Nordgren RE, Walters SE, et al. Timing of prenatal stressors and autism. J Autism Dev Disord. 2005; 35(4):471-8.

57. Maimburg RD, Vaeth M. Perinatal risk factors and infantile autism. Acta Psychiatr Scand. 2006;114(4): 257-64.

58. Rai D, Lee BK, Dalman C, Golding J, Lewis G, Magnusson C. Parental depression, maternal antidepressant use during pregnancy, and risk of autism spectrum disorders: population based case-control study. BMJ. 2013;346:f2059.

59. El Marroun H, White TJ, van der Knaap NJ, Homberg JR, Fernandez G, Schoemaker NK, et al. Prenatal exposure to selective serotonin reuptake inhibitors and social responsiveness symptoms of autism: population-based study of young children. Br J Psychiatry. 2014;205(2):95-102.

60. Croen LA, Grether JK, Yoshida CK, Odouli R, Hendrick V. Antidepressant Use During Pregnancy and Childhood Autism Spectrum Disorders. Arch Gen Psychiat. 2011;68 (11): 1104-12.

61. Sorensen MJ, Gronborg TK, Christensen J, Parner ET, Vestergaard M, Schendel D, et al. Antidepressant exposure in 
pregnancy and risk of autism spectrum disorders. Clin Epidemiol. 2013;5:449-59.

62. Hviid A, Melbye M, Pasternak B. Use of Selective Serotonin Reuptake Inhibitors during Pregnancy and Risk of Autism. New Engl J Med. 2013;369 (25): 2406-15.

63. Gardener H, Spiegelman D, Buka SL. Prenatal risk factors for autism: comprehensive meta-analysis. Br J Psychiatry. 2009;195(1):7-14.

64. Langridge AT, Glasson EJ, Nassar N, Jacoby P, Pennell C, Hagan R, et al. Maternal conditions and perinatal characteristics associated with autism spectrum disorder and intellectual disability. PLoS One. 2013; 8(1):e50963.

65. Mahoney AD, Minter B, Burch K, Stapel-Wax J. Autism spectrum disorders and prematurity: a review across gestational age subgroups. Adv Neonatal Care. 2013;13 (4): $247-$ 51.

66. Limperopoulos C, Bassan H, Sullivan NR, Soul JS, Robertson RL, Jr., Moore M, et al. Positive screening for autism in expreterm infants: prevalence and risk factors. Pediatrics. 2008;121(4):758-65.

67. Johnson S, Hollis C, Kochhar P, Hennessy E, Wolke D, Marlow N. Autism spectrum disorders in extremely preterm children. Journal of Pediatrics. 2010; 156 (4):525-U27.

68. Schieve LA, Tian LH, Baio J, Rankin K, Rosenberg D, Wiggins $\mathrm{L}$, et al. Population attributable fractions for three perinatal risk factors for autism spectrum disorders, 2002 and 2008 autism and developmental disabilities monitoring network. Ann Epidemiol. 2014;24(4):260-6.

69. Hultman CM, Sparen $P$, Cnattingius $S$. Perinatal risk factors for infantile autism. Epidemiology. 2002; 13(4):417-23.

70. Feng XL, Xu L, Guo Y, Ronsmans C. Factors influencing rising caesarean section rates in China between 1988 and 2008. Bulletin of the World Health Organization. 2012;90 (1):30-9.

71. Guinchat V, Thorsen $\mathrm{P}$, Laurent $\mathrm{C}$, Cans $\mathrm{C}$, Bodeau N, Cohen D. Pre-, peri- and neonatal risk factors for autism. Acta Obstet Gynecol Scand. 2012;91(3):287-300.

72. Dickerson AS, Rahbar MH, Bakian AV, Bilder DA, Harrington RA, Pettygrove S, et al. Autism spectrum disorder pr- evalence and associations with air concentrations of lead, mercury, and arsenic. Environ Monit Assess. 2016;188 (7): 407.

73. Fujiwara T, Morisaki N, Honda Y, Sampei M, Tani Y. Chemicals, Nutrition, and Autism Spectrum Disorder: A MiniReview. Front Neurosci. 2016;10:174.

74. Kalkbrenner AE, Schmidt RJ, Penlesky AC. Environmental chemical exposures and autism spectrum disorders: a review of the epidemiological evidence. Curr Probl Pediatr Adolesc Health Care. 2014; 44(10):277-318.

75. Flores-Pajot MC, Ofner M, Do MT, Lavigne E, Villen-euve PJ. Childhood autism spectrum disorders and exposure to nitrogen dioxide, and particulate matter air pollution: A review and meta-analysis. Environ Res. 2016;151:763-76.

76. Gong T, Dalman C, Wicks S, Dal H, Magnusson C, Lundholm $\mathrm{C}$, et al. Perinatal exposure to traffic-related air pollution and autism spectrum disorders. Environ Health Perspect. 2017;125(1):119-26.

77. Sealey LA, Hughes BW, Pestaner JP, Steinemann A, Pace DG, Bagasra O. Environmental factors may contribute to autism development and male bias: Effects of fragrances on developing neurons. Environmental Research. 2015;142:731-8.

78. Knickmeyer RC, Baron-Cohen S. Fetal testosterone and sex differences in typical social development and in autism. J Child Neurol. 2006;21(10):825-45.

79. Tordjman S, Somogyi E, Coulon N, Kermarrec S, Cohen D, Bronsard G, et al. Gene x Environment interactions in autism spectrum disorders: role of epigenetic mechanisms. Front Psychiatry. 2014;5:53.

80. Hertz-Picciotto I, Croen LA, Hansen R, Jones CR, van de Water J, Pessah IN. The CHARGE study: an epidemiologic investigation of genetic and environmental factors contributing to autism. Environ Health Perspect. 2006;114(7): 1119 -25 .

81. Kim D, Volk H, Girirajan S, Pendergrass S, Hall MA, Verma SS, et al. The joint effect of air pollution exposure and copy number variation on risk for autism. Autism Res. 2017;10 (9):1470-80.

How to cite this article:

Ou J, Liu R, Shen Y, Xia K, Zhao J. An overview on genetic and environmental risk of Autism Spectrum Disorder. Glob Clin Transl Res. $2019 ; 1(1): 37-44$.

Copyright (C) 2019 by the Global Clinical and Translational Research. 